\title{
Post-traumatic artificial lens implants (pseudophakoi) in children
}

\author{
C. D. BINKHORST, M. H. GOBIN, AND P. A. M. LEONARD \\ Terneuzen, Netherlands
}

Stintzy (1966), in a review of $45^{\circ}$ cases of eye injuries, mostly unilateral, in children, reported the development of cataract in 26 per cent. Traumatic cataract, if not complicated by severe damage to other structures of the eye and if successfully treated by surgery, presents the surgeon and the child with the problems of unilateral aphakia. The optical correction of the latter is the crux of successful functional recovery.

In the adult aphakic patient visual acuity can be and usually is preserved for long응 periods of life, even without optical correction. Also binocularity has been demonstrated $\rightarrow$ in adults in whom a contact lens or lens implant has been fitted several decades after lens? injury. This, however, does not hold true in cases of lens injury in infancy and childhood. The younger the child and the longer the interval between injury and clearing of the $\vec{\oplus}$ pupil, the more chance there is of irreparable loss of visual acuity and of binocularity. Such loss is certain to occur when no correction at all is prescribed or when the eye is equipped only with a spectacle glass (Juler, I92 I ; McKinna, I96I).

\section{Contact lenses}

The development of contact lenses seemed to offer more hope to the unilateral aphakic child, and many reports have appeared, including those of Ridley (I953), Spaeth andङ O’Neill ( I 96o), Blaxter ( 1963 ), Ruben ( 1963 ), Magnard, Hugonnier-Clayette, Hugonnier, and Bourelly (1964), Riehm and Thiel (1965), Bronner (1966), Bonnet, Gerhard, and? Massin (1966), and Offret, Coscas, and Huet (1967).

The corneal contact lens is most often used for the purpose to-day, but high plus corneato lenses tend to downward displacement, thus causing vertical diplopia (Bronner and Gerhard, I958), and the corneo-scleral lens is preferred by many authors (Ridley, i $953 ;$ Bronner and Gerhard, I958; Spaeth and O'Neill, r96o; Blaxter, I963; Lake and Manson I964; Bonnet and others, I966). Because of their increased weight, however, the latter also can give rise to vertical phoria and diplopia.

Although we have fitted young children and even infants with contact lenses (as did Girard, I961 ; Ruben, I963; Blaxter, I963; Cassady, I964; Lake and Manson, I964), it iঙ̆ generally agreed that to fit children below a certain age has little practical value. Ridley ( 1953) places the critical age at ı years; Spaeth and O'Neill (1960) at Io years; Magnard and others (1964) at 7 years; Saraux (1966) at 6 years; Bonnet and others (1966) at 7 years Bronner (1966) at 8 years; Offret and others (1967) at 5 years. Several authors mention major difficulties even in children above these age limits. Toleration of the lens largely depends on the cooperation not only of the child, but also of the parents. Many unilatera aphakic patients give up wearing their contact lens sooner or later. Bonnet and otherș (1966) found that, of 308 adult unilateral aphakics, nearly 80 per cent. had given upD wearing their contact lens after io years. There is no reason to suppose that results ino 
children are likely to be better than in adults. In a child even temporary discontinuation of the contact lens can be disastrous (Ghoyce, 1964).

Even in the successfully-fitted child with good visual acuity and parallel eyes, there are good reasons for future functional failure, the main one being the strong tendency towards suppression in children. This results from the generally under-developed binocular capacity in infancy and childhood. Whenever a child finds it difficult to fuse the images of both eyes, it escapes the problem by suppression. This may occur at relatively low levels of aniseikonia, which is more often seen in contact lens correction than in pseudophakia. Comparing the work of Giraud, Friedman, Moore, and Blau (1962) with our own results, an average difference of $\mathrm{I} \cdot 9$ per cent. was found in image size in pseudophakia and an average difference of 6.9 per cent. in contact lens correction. Suppression may also occur in cases of contact lens-induced image disparity, especially in the vertical direction. Thus the child will remain uniocular and become amblyopic, and squint may complete the picture. It is recognized by experienced authors (Lyle, I953; Spaeth and O'Neill, I96o) that orthoptic training is seldom successful in such cases.

If contact lenses cannot prevent suppression and squint, their curative effect is obviously negligible. Traumatic cataract in children very frequently gives rise to suppression and the development of squint at an early stage (Binkhorst and Gobin, 1967). There are a few isolated reports of a straightening effect of contact lenses (Ogle, Burian, and Bannon, (I958), but generally contact lenses, even if accompanied by the use of prisms, muscle surgery, or orthoptic training, has had little success. On the contrary, they have been blamed for causing or aggravating squint by Lyle (1953); Spaeth and O'Neill (I96o), Blaxter (1963), Magnard and others (1964), Binkhorst and Gobin (1964, 1967), Lake and Manson (1964), Riehm and Thiel (1965), and Bonnet and others (1966).

Our own experience with ten children is significant. In every case either suppression or persistent diplopia occurred, and deviation of the eyeball was never cured, either spontaneously or after muscle surgery. In a Io-year-old child esotropia was initiated by the contact lens. In a 3-year-old child esotropia was present as long as the contact lens was worn and disappeared after its removal. In another ro-year-old child esotropia grew worse after the application of the contact lens. In two children, both 3 years old, initial exotropia became esotropia with the contact lens. We thought at first that every patient with unilateral aphakia should be given a chance with a contact lens (Binkhorst and Gobin, 1964), but we now feel that in children the lens should not be used as it reduces the chance of binocular re-education (Binkhorst and Gobin, 1967).

\section{Intraocular lenses}

In the last 20 years intraocular lenses (pseudophakoi) have been used for the correction of aphakia. They have many practical advantages over contact lenses and there is no doubt that their optical effect is superior. A well-fixed and well-centred lens implant produces a stable retinal image with stable space localization. Pseudophakoi, also, can be so made as to give the unilateral aphakic patient a fair chance of iseikonia or at least of a minimum and tolerable aniseikonia (Girard and others, I962; Binkhorst and Gobin, 1964). Implants thus offer the best chance of re-establishment of binocularity in cases of aphakia. In children, in whom binocularity is so readily lost and so hard to restore, there is a strong indication for the use of implants.

Many techniques of lens implantation have failed to give reliable long-term results, and reports on their use in children are scarce. In the fourteen earliest cases of the series 
presented here, the anterior chamber lens with angle fixation (Dannheim, I 955) was used, and in the others anterior chamber lenses with diaphragm fixation. We feel that the latterô is a safe procedure and gives good stability (Binkhorst, I959, I967a, b).

IRIS CLIP LENS

The "iris clip lens" has proved its value in over 400 adult patients (Binkhorst and $\stackrel{\mathbb{\Omega}}{\circ}$ Leonard, I967). Although used mainly after intracapsular cataract extraction, it can also be used after extracapsular extraction. Whereas after intracapsular extraction it is held $\vec{\circ}$ in place almost entirely by the iris diaphragm, after extracapsular extraction it is supported $\vec{\Xi}$ by the iris diaphragm and also by the secondary membrane diaphragm (Fig. I).

In children this type of lens implant is indicated when posterior synechiae have failed to응. form after extracapsular extraction. The anterior chamber should be deep enough to prevent the anterior wire loops touching the endothelium as the secondary membrane may 00 be responsible for a slightly more forward position than after intracapsular extraction. $\frac{0}{\infty}$ The "iris clip lens" was used in only one of the series presented here (Case 2 I, Fig. 2).
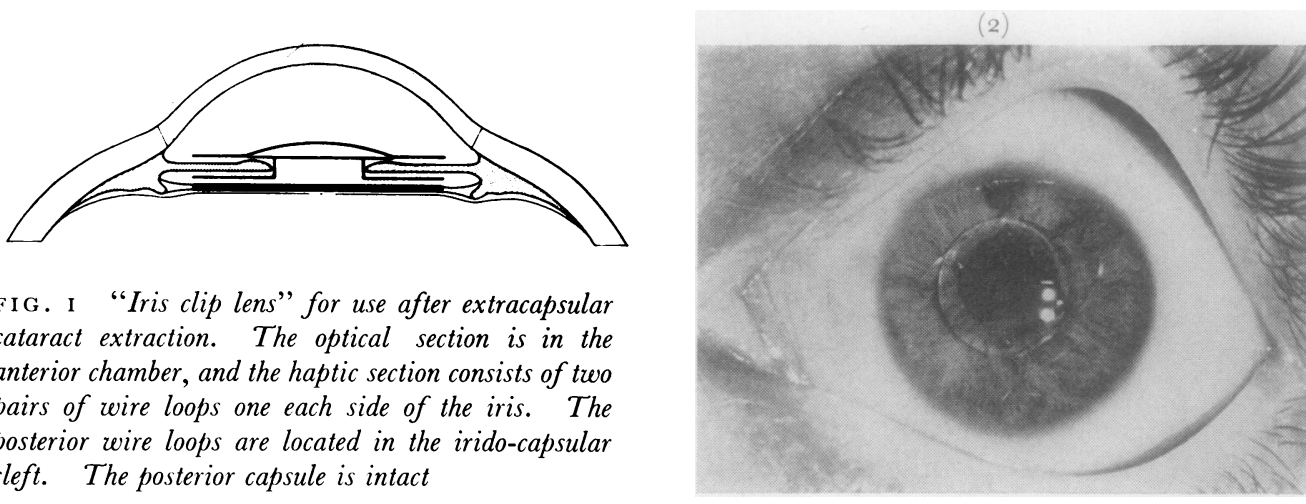

FIG. I "Iris clip lens" for use after extracapsular cataract extraction. The optical section is in the anterior chamber, and the haptic section consists of two pairs of wire loops one each side of the iris. The posterior wire loops are located in the irido-capsular cleft. The posterior capsule is intact

FIG. 2 Case $2 \mathrm{I}$, injured at the age of I I years. "Iris clip lens" implanted 3 years later. Clear posterior capsule. No posterior synechiae. Miotics are being used for extra stability.

IRIDO-CAPSULAR LENS

During the past 3 years the "irido-capsular lens" has been used satisfactorily in nearly fifty implantations in patients of all ages with all types of cataract. It was used exclusively for combined iris diaphragm and secondary membrane fixation, being supported by one $N$ pair of wire loops buried in the partially obliterated irido-capsular cleft (Fig. 3). This type of implant is satisfactory for most children with traumatic cataract and was used in $N_{\omega}^{N}$ eleven children in this series (Figs 4 to 6, opposite).

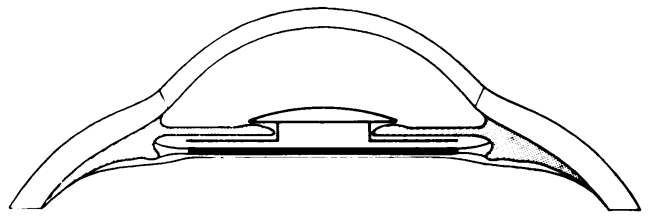

FIG. 3 "Irido-capsular lens" for use after extracapsular cataract extraction. The optical section is in the anterior chamber, and the haptic section consists of a pair of wire loops located in the irido-capsular cleft and embedded by posterior iris synechiae. The posterior capsule is intact 

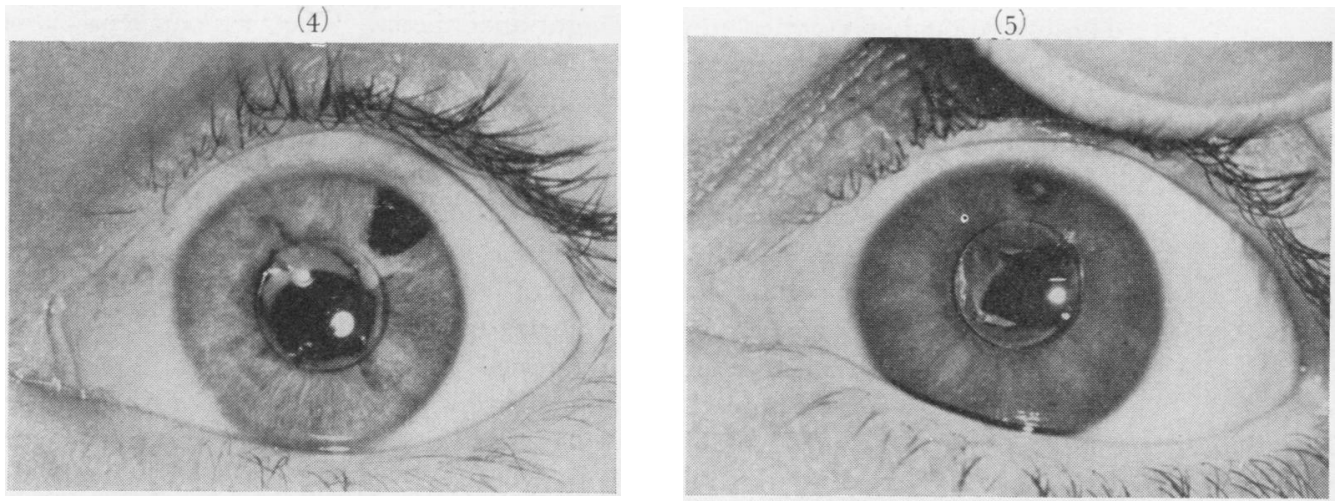

FIG. 4 Case I I, injured at the age of 6 years. "Irido-capsular lens" implanted I year later. Secondary membrane with clear centre. Implant held in place by posterior synechiae.

FIG. 5 Case 19, injured at the age of 10 years. "Irido-capsular" lens implanted 9 years later. It is held in place by posterior synechiae. The thick secondary membrane was partly excised after the implantation.

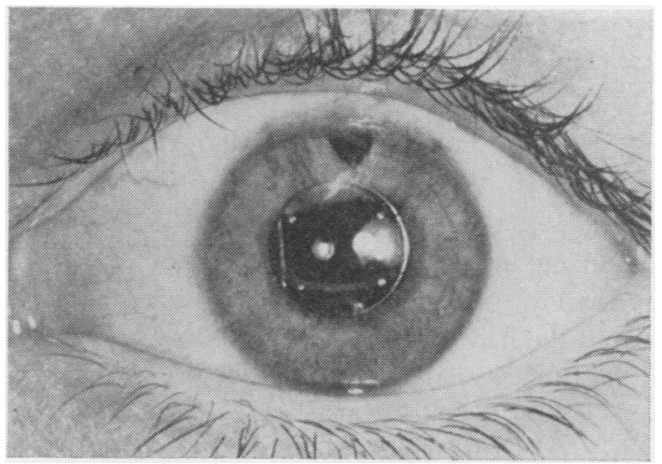

FIG. 6 Case 25, injured at the age of 14 years. "Irido-capsular lens" implanted 3 years later. Secondary membrane with clear centre. Implant held in place by posterior synechiae

\section{Surgical technique}

\section{"Iris clip lens"}

This can be manufactured to individual specifications, but a standard type is usually used by the authors. The optical section is designed as a simple convexo-plano acrylic lens with a diameter of 4 to $5 \mathrm{~mm}$., a centre thickness of $0.5 \mathrm{~mm}$., and a radius of curvature of the anterior surface of $7.6 \mathrm{~mm}$. Its equivalent power in the aqueous humour is $20 \cdot 26$ dioptres. It is entirely located in the anterior chamber, immediately in front of the pupil, without touching the iris. It has one pair of $\mathrm{o}_{1} \mathrm{I} \mathrm{mm}$. Supramid wire loops level with the lens and lying in front of the iris diaphragm, and one pair of $0.2 \mathrm{~mm}$. loops lying just behind the iris diaphragm. The clearance between the loops on each side is 0.5 to $0.75 \mathrm{~mm}$., allowing just enough room for the iris to lie between them (Fig. I). The distance between the tips of the loops is $8 \mathrm{~mm}$. The loops act as safeguards against forward or backward displacement, but the actual fixation and centring are performed by the iris sphincter muscle at the four posterior loop attachments. For this purpose 2 per cent. pilocarpine eyedrops are instilled twice daily. Only in rare cases, in which adhesions develop between the iris and the posterior loop attachments, is this unnecessary. 
The operation is performed under general anaesthesia. The "iris clip lens" is used in specia cases where extracapsular extraction has failed to form adhesions between iris and secondary mem-음 brane. The usual measures for intraocular surgery are taken. The only special precautions in: implantation surgery are the preoperative administration of a broad spectrum antibiotic and the 3-hourly instillation of a $\mathrm{O} \cdot \mathrm{I}$ per cent. solution of dexamethasone $2 \mathrm{I}$-phosphate (Decadron). Pre음 operative mydriasis is produced by instillation of homatropine. An ab externo incision, with knife $\frac{\bar{\sigma}}{\bar{D}}$ and scissors, must be made wide enough for the insertion manoeuvre to be comfortable. If not already present a peripheral iris coloboma is cut. As a rule the pseudophakos is held with the loops horizontally and is eased into position by zigzag movements; the forceps is then removed and the anterior chamber is irrigated with a $\mathrm{I}: \mathrm{l} 00$ acetylcholine solution.

In the case of a very wide pupil the anterior chamber is irrigated with acetylcholine before removing the forceps. If the pupil is small the implant is held with the loops vertically and the upper iriso sector is carefully placed between the two pairs of loops with a blunt iris hook while the corneal flap. is lifted. Fedorov (1967) has proposed a modification of the "iris clip lens" having the anterior ande posterior loops placed cross-wise. Before the wound is closed, the anterior chamber is reformed byo completely filling it with air to prevent the implant rubbing the corneal endothelium during suturing.r There is no risk of migration of air behind the iris. The wound is closed with at least five virgin silk $\overrightarrow{0}$ end-to-end sutures and covered by the limbal-based conjunctival flap. The eye is not padded, bus is protected by a shield, and if lid closure is insufficient the cornea is protected by pilocarpine oint $-\vec{D}$ ment 2 per cent. The eye can be observed and treated through the $\mathrm{I} \cdot 5$ to $2 \mathrm{~cm}$. central hole in the shield. Postoperative treatment consists of 3 -hourly instillations of a $0 \cdot 1$ per cent. solution of dexamethasone $2 \mathrm{I}$-phosphate (Decadron) for the first week, gradually diminishing to four times $\vec{\bullet}$ daily for 6 to 8 weeks. 2 per cent. pilocarpine eye drops are instilled twice daily.

\section{"Irido-capsular lens"}

Again a standard implant is usually used by the authors. The optical part is the same as in the "iris clip lens" and this is also located entirely in the anterior chamber immediately in front of the pupil without touching the iris. The fixation mechanism requires a strong secondary membrane $\vec{B}$ and adhesions between this membrane and the iris. The "irido-capsular lens" has only one pair of wire loops; these lie behind the lens and are buried in the irido-capsular cleft (Fig. 3). Irido-? capsular adhesions embedding the loops guarantee excellent stability and even prevent inadequate. mydriasis. The usual distance between the tips of the loops is $8 \mathrm{~mm}$., but this can be slightly응. modified by the surgeon if necessary. Again, contact between the implant and the eye is minimal.:

In cases of soft cataract, one-stage surgery is time-saving and sometimes advisable. Preparatory needling is recommended a few days to a week before the removal of the cataract. Immediatelyo after insertion the pupil should be made to fit firmly around the four loop attachments, producing ideal centring and giving extra support to the implant. This pupillary action should be maintained음 until irido-capsular adhesions have formed. Careful administration of mydriatics is then started to give the aqueous as much access to the lens remnants as possible in order to clear the pupil without affecting the stability of the lens. The effectiveness of the irido-capsular adhesions can be tested under maximum mydriasis.

In two-stage surgery, to ensure that efficient irido-capsular adhesions embed the wire loops, the latter should be placed exactly where the adhesions have been cut. If no such adhesions are present, it may be decided to use the "iris clip lens" instead.

The "irido-capsular lens" has the advantage of reducing the risk of touching the cornea if the secondary membrane tends to push the lens forwards. This is important in young children or $\stackrel{9}{\rightarrow}$ infants, whose eyes are not fully grown, as well as in eyes with a shallow anterior chamber or an 0 eccentric pupil. Because of the firm fixation in the irido-capsular cleft, this implant can be used in cases of iris coloboma.

For the loops an inert metal wire (platina-iridium) has been chosen. It is slightly heavier than $\stackrel{\mathbb{D}}{\varrho}$ Supramid but this is easily tolerated where the pseudophakos is fixed to a rigid secondary membrane. 
The insertion of an "iris clip lens" or an "irido-capsular lens" into the aphakic eye is an easy and a safe procedure as long as the posterior capsule of the crystalline lens is intact and there is no possibility of the vitreous entering the anterior chamber. Though not impossible, insertion becomes hazardous if the posterior capsule is perforated at the time of the injury, or during cataract extraction, or as a result of needling the secondary membrane. In such cases corneal dystrophy, uveitis, or secondary glaucoma may arise from the presence of vitreous in the anterior chamber, and the vitreous may interfere with the position of the implant.

If needling or excision of the secondary membrane is necessary, therefore, it should always be done at a later stage after the implantation, when the vitreous is kept out of the anterior chamber by the implant.

\section{Results and discussion}

From July, I959, to May, 1967, 26 children have been given a lens implant because of unilateral traumatic cataract. Their ages at the time of injury varied from 2 to 14 years, the interval between injury and implantation ranged from 2 months to 12 years, and the follow-up period from almost 9 to at least one year (Table I).

Table I Results in 26 children with unilateral post-traumatic pseudophakia

\begin{tabular}{|c|c|c|c|c|c|c|c|c|c|}
\hline \multirow{3}{*}{$\begin{array}{l}\text { Case } \\
\text { no. }\end{array}$} & \multirow{3}{*}{ Age at injury (yrs) } & \multirow{3}{*}{$\begin{array}{l}\text { Interval } \\
\text { between } \\
\text { injury } \\
\text { and } \\
\text { implan- } \\
\text { tation } \\
(y r s)\end{array}$} & \multirow{3}{*}{$\begin{array}{l}\text { Corrected } \\
\text { visual } \\
\text { acuity }\end{array}$} & \multirow{3}{*}{$\begin{array}{l}\text { Residual } \\
\text { deviation } \\
\left({ }^{\circ}\right)\end{array}$} & \multicolumn{5}{|c|}{ Binocular vision (Fusion) } \\
\hline & & & & & \multirow{2}{*}{$\begin{array}{l}\text { First } \\
\text { degree }\end{array}$} & \multirow{2}{*}{$\begin{array}{l}\text { Second degree } \\
\left({ }^{\circ}\right)\end{array}$} & \multicolumn{3}{|c|}{ Third degree } \\
\hline & & & & & & & $\begin{array}{l}\text { Synopio- } \\
\text { phore }\end{array}$ & $\begin{array}{l}\text { Fly } \\
\text { test }\end{array}$ & $\begin{array}{l}\text { Wirt } \\
\text { test }\end{array}$ \\
\hline I & Two & 3 & $0 \cdot 0 I^{*}$ & +5 & - & - & - & - & - \\
\hline 2 & Two & $4 / 12$ & $0 \cdot 8$ & +13 & - & - & 一 & - & - \\
\hline 3 & Three & $\mathrm{I} \frac{1}{2}$ & $0 \cdot I$ & $+2 \mathrm{~L} / \mathrm{R}_{3}$ & - & - & - & - & - \\
\hline 4 & Three & 1 & $I \cdot 0$ & o & + & -6 to +6 & + & + & $\mathbf{0} \cdot \mathbf{I}$ \\
\hline 5 & Three & $4 / 12$ & I $\cdot 0$ & o & + & -3 to +2 & + & + & 0.6 \\
\hline 6 & Three & $5 / 12$ & $I \cdot 25$ & o & + & 0 to -2 & - & - & - \\
\hline 7 & Three & $4 / 12$ & $0 \cdot 6$ & o & + & - & - & - & - \\
\hline 8 & Four & $3 / 12$ & 0.6 & o & + & -6 to +3 & + & + & 0.5 \\
\hline 9 & Five & 3 & $0 \cdot 3$ & -5 & + & - & - & - & - \\
\hline 10 & Six & $3 / 12$ & 0.8 & o & + & -4 to +6 & + & + & 0.8 \\
\hline I I & Six (Fig. 4) & I & $0 \cdot 5$ & o & + & +3 to +17 & - & - & - \\
\hline 12 & Seven & $1 \frac{1}{2}$ & $I \cdot O$ & o & + & -7 to 0 & - & + & 0.7 \\
\hline I3 & Eight & $\mathrm{I} \frac{1}{2}$ & $0 \cdot 8$ & o & + & 0 to +30 & + & + & 0.5 \\
\hline 14 & Eight & $5 / 12$ & $I \cdot 25$ & o & + & -2 to +8 & + & + & $1 \cdot 4$ \\
\hline I 5 & Eight & 12 & $I \cdot O$ & o & + & +3 to +7 & + & - & - \\
\hline 16 & Nine & I & $0 \cdot 3$ & o & + & -3 to +8 & - & - & - \\
\hline 17 & Ten & 2 & 0.6 & o & + & -2 to +7 & + & + & - \\
\hline 18 & Ten & $\mathbf{I}$ & $0 \cdot 8$ & o & + & o tó + 15 & + & + & $0 \cdot 6$ \\
\hline 19 & Ten (Fig. 5) & 9 & $I \cdot O$ & o & + & -4 to +8 & - & + & 0.6 \\
\hline 20 & Ten & I & $\mathbf{I} \cdot 25$ & o & + & -4 to +9 & - & + & $0 \cdot 3$ \\
\hline 21 & Eleven (Fig. 2) & 3 & $1 \cdot 6$ & o & + & -2 to +10 & + & + & $0 \cdot 7$ \\
\hline 22 & Twelve & $2 / 12$ & $2 \cdot 0$ & o & + & -8 to +15 & + & + & 0.8 \\
\hline 23 & Thirteen & 6 & $\mathrm{I} \cdot 6$ & o & + & -6 to +20 & - & + & $0 \cdot 7$ \\
\hline 24 & Thirteen & 6 & $0 \cdot 6$ & o & + & -3 to +10 & + & + & - \\
\hline 25 & Fourteen (Fig. 6) & 3 & $I \cdot 25$ & o & + & -4 to +14 & - & - & - \\
\hline 26 & Fourteen & $6 / 12$ & $1 \cdot 6$ & o & + & -7 to +16 & + & - & 0.5 \\
\hline
\end{tabular}

* eccentric fixation 
Only one child with severe perforating injury was treated by us from the beginning, al a the others having been referred to us after they had been treated elsewhere. Some cameo with traumatic cataracts, others as aphakics with a dense secondary membrane or with $a$ clear pupil. Sometimes vitreous was present in the anterior chamber as a result of the injury or as a consequence of surgery. In many the neglect of functional training had lede to deep amblyopia and squint. Some had been equipped with a contact lens with no orthoptic training. The result was that in many cases the interval between the injury and the implantation was unnecessarily long. The ultimate results would have beeno better if the directions for the treatment of lens injury and of traumatic cataract in children that we have outlined in previous publications (Binkhorst and Gobin, I964, 1967), had been followed.

\section{Visual acuity}

This was measured with Snellen's E-test at $5 \mathrm{~m}$. (Fig. 7). In two cases the final visuapo acuity and fixation were poor. One came under treatment 3 years after the injury and in both the occlusion which had been prescribed had been neglected. In all the othero children the visual acuity is now fair to good. In most cases a weak additional spectaclecorrection is worn, and in one case with central scarring of the cornea visual acuity was improved by a plano contact lens.

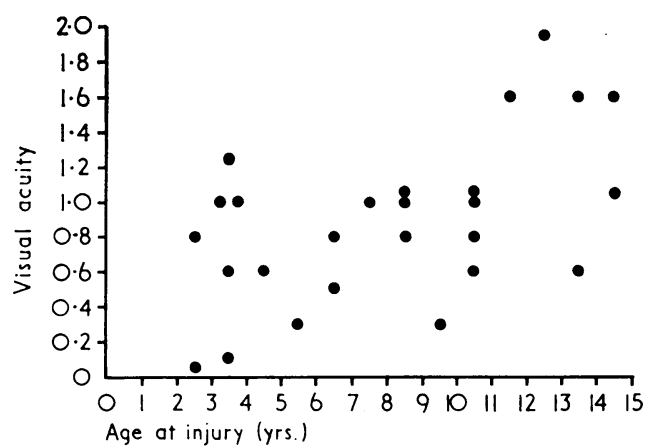

FIG. 7 Visual acuity measured by Snellen's E-tesहै in 26 children with unilateral lens implants, injured at ages ranging from 2 to 44 years

Recovery of visual acuity partly depends on such factors as the nature of the injury ando the success of surgical intervention. Especially in children, however, it largely depends on quick and efficient functional re-education. We feel that this is best effected with lens? implantation which requires minimal cooperation and produces no discomfort. In many을 young children amblyopia is already very deep after a few weeks. Suppression starts aț the time of the injury (Binkhorst and Gobin, 1967). Even in seemingly hopeless cases however, amblyopia has been cured after lens implantation and with prolonged occlusion of the other eye. So six out of eight children under the age of 5 years regained fair to good visual acuity.

Other workers' reports on unilateral aphakic children equipped with a contact len claim good visual acuity only in older children, and Bonnet and others ( 1966) frankly:? admitted that visual acuity in those under the age of 7 years was usually poor.

The better the visual acuity or at least the better it matches that of the other eye, the better is the chance of regaining binocular vision. Visual acuity of at least 0.5 is generally命 estimated as giving a chance of fusion. This degree of acuity was present in 2 I out of our 
26 children. For perfect fusion still better visual acuity is necessary. Offret and others ( 1967 ) found stereopsis only in cases with 0.7 to 0.8 visual acuity. Bronner and Gerhard (1959) found "useful stereopsis" only in patients with 0.8 to $1 \cdot 0$ visual acuity. These were all adults and it is likely that in children such high levels of visual acuity are even more necessary. Visual acuity of at least $\mathrm{I} \cdot \mathrm{O}$ was present in eleven out of our 26 children.

We have learned that during re-education it is very important to check visual acuity carefully and at regular intervals, so as to reveal any deterioration due to anatomical or sensory factors.

\section{Squint}

The position of the eye was tested with the Maddox cross at $\mathrm{I} \mathrm{m}$. In only four of the younger children was there a residual deviation, in three convergent and in one divergent. In one child convergent squint was accompanied by vertical deviation. Though the resistant cases occurred amongst the youngest children, five out of eight under the age of 5 years had no residual deviation.

Squint was a frequent complication when the patients were first seen. Deviation problems arose in all but five cases. Twenty were squinting before cataract surgery was undertaken. This supports our opinion that suppression starts with cataract development and that the injured eye should be occluded (Binkhorst and Gobin, 1967). The high incidence and early occurrence of squint in unilateral traumatic cataract is also mentioned by Magnard and others (1964), who quoted Rougier (1954), Maurer (1964), and Ruben (1964). Whereas Magnard and others (1964) mentioned divergent squint in all but one and convergent squint in only one case, we found divergent and convergent squint equally divided amongst our patients, who were significantly younger. In one of our cases a convergent squint was initiated by contact lens correction of the aphakic eye. We could not confirm the opinion of Lyle (1953), Magnard and others (1964), and Maurer (1964), that vertical squint is common in these patients. Vertical deviation may be explained by the very application of contact lenses. We had only one patient with a residual vertical deviation, and this child had been fitted with a contact lens before the implantation.

A spontaneous cure of the deviation in nine out of 2 I children with squint followed the lens implantation without any orthoptic training. This has never happened after fitting a contact lens even with intensive orthoptic training. Some authors report the same negative result (François, I958; Saraux, I966), whereas others had positive results in older patients (Lyle, I953; Ridley, I953; Constantine and McLean, I954; Gettes and Ravdin, 1949; Magnard and others, 1964). Eight children had the deviation corrected by muscle surgery, most of them some time after the lens implantation. In one child a recession of the lateral rectus muscle was performed at the same time as the implantation.

Fusion

All children were tested on first, second, and third degree fusion.

FIRST DEGREE FUSION (simultaneous perception) This could be demonstrated on the synoptophore in 23 of our 26 cases. The three youngest children, all with residual convergent squint, were suppressing.

SECOND DEGREE FUSION This was demonstrated on the synoptophore in 21 of the 26 children. The fusional amplitude, as recorded at the first examination and without 
insistence, varied from 2 to $30^{\circ}\left(\right.$ average $\left.13.5^{\circ}\right)$. Fusion in patients with unilateral lens implants is stable and vision is comfortable. If they complain of diplopia, it is only for a very short period after the implantation, whereas patients with contact lenses may suffer from persistent diplopia (Magnard and others, I 964), from periodic lapses of fusion (Riehm and Thiel, 1965), or from "visual discomfort" (Fontan, Thalabard, and Robert, I962). Fusion in patients with unilateral implants is unconditional; it is less affected by such $\frac{\bar{\sigma}}{\bar{c}}$ factors as the absence of accommodation or loss of interest and not so easily broken by $\vec{\Phi}$ provocative measures such as occlusion or weak prisms. This characteristic of lens $\stackrel{\varrho}{\otimes}$ implants is especially valuable in children in whom fusion capacity is still underdeveloped ${ }_{\vec{O}}^{\text {s }}$ and the tendency to suppression is strong.

To what degree the absence of accommodation in one eye unfavourably influences the stability of fusion, is a matter of opinion. Most authors dealing with unilateral aphakics $\partial$ wearing one contact lens think that it is an important obstacle in binocular re-education? (Cowan, I949, I953; Cross, I949; Hirtenstein, I950; Bronner and Gerhard, I958; Ogle ${ }^{\omega}$ and others, I958; Magnard and others, 1964). Suppression is more likely to occur inco children if a static aphakic or pseudophakic eye has to compete with a highly dynamic $\vec{\infty}$ phakic eye. The absence of accommodation in one eye produces retinal images not only 9 of different acuity but also with considerable differences in size; these differences are liable $\vec{\square}$ to provoke diplopia or suppression. Differences in visual acuity can be eliminated with ace bifocal spectacle lens preferably with a large lower segment or (as we did in a few children) $\stackrel{\text { 吕 }}{\oplus}$ with a spectacle lens, slightly overpowered for distance and slightly underpowered for $\vec{\bullet}$ near, thus giving tolerable performances at all distances. The prescription of gradiento glasses ("Varilux") has been suggested by Apers (personal communication). The prescription of a near addition for both eyes is strongly advised to counteract accommodation-induced aniseikonia.

THIRD DEGREE FUSION (stereopsis) This was tested on the synoptophore, with the Polaroid fly stereotest, and with the Wirt stereotest. We found a positive performance on $\overrightarrow{\overrightarrow{0}}$ the synoptophore in thirteen children, with the Polaroid fly stereotest in fifteen, and with the Wirt stereotest in fourteen, the scores varying from $\mathrm{o}_{\mathrm{I}} \mathrm{I}$ to $\mathrm{I} \cdot 4$. In seventeen children one or more stereotests were positive. According to Bronner and Gerhard (1959), the tests used are not the easiest to appreciate even for adults. We must also remember that: stereoscopic capacity is probably only fully developed at the age of 8 years, and that it was 3 . not known how the children had performed before the accident. These facts may partlyo account for negative test results. There were positive results in the youngest children as $₹$ well as negative results in the older children. In quite a few cases we observed how initialo negative test performances became positive as the years passed without any orthoptic training. These results should be evaluated against the opinion that contact lens correction in young children does not encourage binocular re-education even with intensive orthoptic training (Cowan, I953; Lyle, I953; Bronner, I966; Saraux, I966). Children N with lens implants thus not only have psychological and social advantages over childrenw with contact lenses but may also benefit throughout their working life. The achievement? of binocular vision is the best guarantee against suppression and thus against amblyopiac and the development of squint.

\section{Conclusions}

The general attitude towards unilateral traumatic cataract in children is changing, in that the practical loss of visual acuity and binocularity need no longer be regarded as inevitable. 
Treatment should be started as soon as possible, and should aim not only at clearing the pupil in the shortest possible time, but also at giving the best correction to the aphakic eye with functional guidance. The case should not be given up until maximum visual acuity and full binocularity have been regained.

Contact lenses may be useful in adults but are unsatisfactory in children, who too often respond with suppression, amblyopia, and squint. Not one good result has been reported with contact lenses in children under 5 years of age.

The development of a safe artificial lens securely fixed by the iris diaphragm offers a better chance of complete functional recovery in children.

Fair to good results were obtained in the majority of 26 children injured at ages ranging from 2 to 14 years, although in most of them treatment was much delayed and many had already developed amblyopia and squint. In several children it took some time, even some years, before third degree fusion (stereopsis) could be đemonstrated.

It is highly important to compensate for the absence of accommodation with the best means available, as this too helps to stabilize fusion.

Functional re-education was effected mainly with occlusion, sustained by muscle surgery, but without orthoptic training. Table II shows the methods used.

Table II Amblyopia and deviation prevention and treatment scheme for children with unilateral lens injury

\begin{tabular}{|c|c|c|c|c|c|}
\hline \multirow{3}{*}{$\begin{array}{l}\text { Pupil } \\
\text { Opaque }\end{array}$} & \multirow{2}{*}{\multicolumn{2}{|c|}{ Vision }} & \multicolumn{3}{|c|}{ Preventive and therapeutic measures } \\
\hline & & & \multirow[t]{2}{*}{ Correction } & \multirow{2}{*}{\multicolumn{2}{|c|}{$\begin{array}{l}\text { Occlusion } \\
\text { Injured eye } 24 \mathrm{hrs}\end{array}$}} \\
\hline & & & & & \\
\hline \multirow[t]{5}{*}{ Clear } & \multicolumn{2}{|l|}{ Improving } & $\begin{array}{l}\text { Pseudophakos } \\
\text { Spectacle glass } \\
\text { Contact lens }\end{array}$ & Other eye $24 \mathrm{hrs*}$ & \\
\hline & \multirow[t]{4}{*}{ Stationary } & \multirow[t]{2}{*}{ Subnormal } & Pseudophakos & Other eye $3 \times 1 \mathrm{hr}$ & $\begin{array}{l}\text { Deviation of long standing: } \\
\text { without delay } \\
\text { Recent deviation: within } \\
6 \text { weeks }\end{array}$ \\
\hline & & & $\begin{array}{l}\text { Spectacle glass } \\
\text { Contact lens }\end{array}$ & \} Alternating & \\
\hline & & \multirow[t]{2}{*}{ Normal } & Pseudophakos & Other eye $\mathrm{I} \mathrm{hr}$ & $\begin{array}{l}\text { Deviation of long standing: } \\
\text { without delay } \\
\text { Recent deviation: within } \\
6 \text { weeks }\end{array}$ \\
\hline & & & $\begin{array}{l}\text { Spectacle glass } \\
\text { Contact lens }\end{array}$ & $\zeta$ Alt & \\
\hline
\end{tabular}

* Constant observation of the fixation and visual acuity of this eye is necessary, and eventually short alternating occlusion of the injured eye is indicated

\section{Summary}

In cases of lens injury in children the following procedure is advised:

(r) First-aid surgery, if necessary.

(2) Occlusion of the injured eye. 
(3) Immediate reference to a centre where artificial lens implantation can be performee and orthoptic control is available.

(4) Clearing of the pupil and implantation of a pseudophakos as soon as possible.

(5) Occlusion of the fellow eye until maximum visual acuity has been regained.

(6) Careful binocular re-education by gradual reduction of occlusion.

(7) If deviation is present and not likely to be cured spontaneously, muscle surgery i indicated.

(8) Periodic testing of visual acuity for early detection of secondary cataract or suppres sion.

\section{References}

APERS, R. Personal communication BINKHORST, C. D. (I959) Trans. ophthal. Soc. U.K., 79, 569

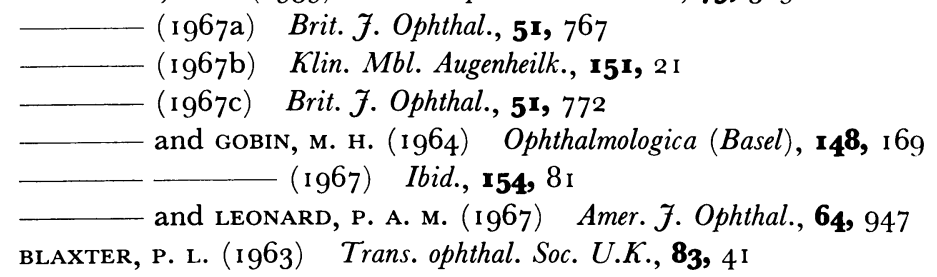

BonNet, R., Gerhard, J. P., and massin, м. (1966) "Rapport annuel", in Bull. Soc. Ophtal. Fr

(numéro special), p. 173

BRonNer, A. (ig66) Bull. Soc. Ophtal. Fr., p. 607

and GERHARD, J. P. (I958) "Rapport p (1959) Bull. Soc. Ophtal. Fr., p. 703

CASSADY, J. R. (1964) Amer. 7. Ophthal., 56, 305

CHOYCE, P. (1964) "Intraocular Lenses and Implants". Lewis, London

constantine, e. F., and mclean, J. m. (1954) A.M.A. Arch. Ophthal., 51, 2 I 2

cowan, A. (1949) Amer. F. Ophthal., 32, 419

(1953) A.M.A. Arch. Ophthal., 50, 16

cross, A. G. (1949) Brit. J. Ophthal., 33, 42 I

DANnheim, H. (1955) Ber. dtsch. ophthal. Ges. (Heidelberg), 6o, 267

FEDOROV. Personal communication (Quoted by Binkhorst, 1967c)

fontan, P., thalabard, J., and Robert, c. (1962) Ann. Oculist. (Paiis), 195, 248

FRANÇOIS, J. Discussion of Bronner and Gerhard (1958)

Gettes, B. C., and ravdin, E. м. (1949) Amer. F. Ophthal., 32, 850

GIRARD, L. (196I) Highlights Ophthal., 4, 228

GIRARD, L. J., FRIEDMAN, B., MOORE, C. D., BLAU, R. J., BINKHORST, C. D., and GOBIN, M. H. (I962)

Arch. Ophthal. (Chicago), 68, 762

hirTEnstein, A. (1950) Brit. J. Ophthal., 34, 668

JUler, F. (I92 I) Trans. ophthal. Soc. U.K., 41, I 29

LAKE, L. H., and MANSON, N. (1964) Ibid., 84, 687

LYLE, T. KEITH (1953) Ibid., 73, 387

MCKinNa, A. J. (I96i) Amer. F. Ophthal., 52, 43

MAGNARD, hUGONNIER-ClAYeTte, HUGONNIER, and BoURELly (1964) Bull. Soc. Ophtal. Fr., p. 203

MAURER, Y. Quoted by Magnard and others (1964)

offret, G., coscas, G., and hUet, м. (1967) Bull. Soc. belge Ophtal., No. I45, p. 221 
ogle, к. N., Burian, H. м., and bannon, R. E. (1958) A.M.A. Arch. Ophthal., 59, 639 RIDLEY, F. (1953) Trans. ophthal. Soc. U.K., 73, 373

RIEHM, E., and thIEL, H. J. (1965) Klin. Mbl. Augenheilk., 146, 589

ROUGIER (1954) Quoted by Magnard and others (1964)

RUBEN, C. (1963) Discussion of Blaxter (1963), p. 48 (1964) Quoted by Magnard and others (1964)

saraux, H. (1966) Bull. Soc. Ophtal. Fr., 66, ro69

SPAETh, P. G., and o'Neill, P. м. (1960) Amer. J. Ophthal., 49, 548

stintzy. Quoted by Bonnet and others (1966) 